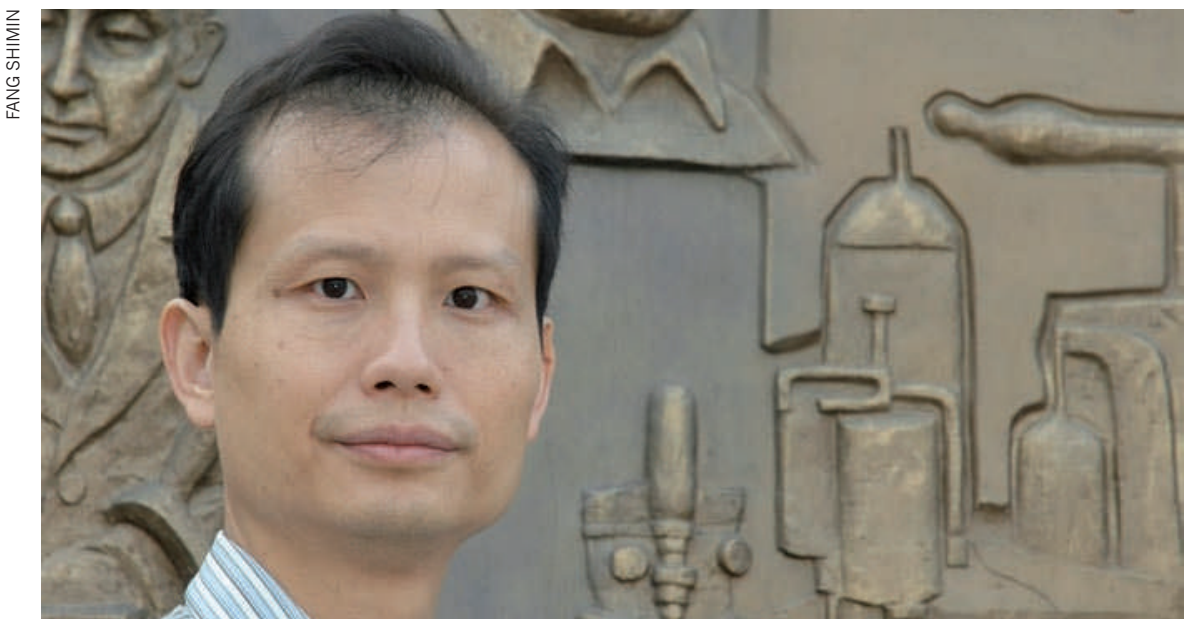

Former biochemist Fang Shimin has made enemies after scrutinizing scientists' reputations.

FRAUD

\title{
Brawl in Beijing
}

\section{Critics of Chinese researchers targeted in physical attacks.}

\section{BY DAVID CYRANOSKI}

S cience can be a rough game in China. On 29 August, on his way home from a tea house in Beijing, Fang Shimin was assaulted. The former biochemist - who for the past decade has run a website exposing scientific fraudsters - was chased by two men, caught and attacked with a hammer.

"I believe they planned to kill me," he says. "The only way to shut me up is to kill me." He escaped with only minor cuts and bruises. In June, Fang Xuanchang, a journalist who had reported on corruption in science in China, was left with more serious injuries after two men assaulted him with steel rods.

On 21 September, police arrested Xiao Chuanguo, a urologist at Tongji Medical College in Wuhan, on suspicion of masterminding both plots. Xiao could not be reached for comment, but has confessed his involvement to Beijing's police. Fang Shimin says Xiao could face 3-10 years in prison - or more if the charges become attempted murder.

Xiao and Fang Shimin have never met or spoken, but their paths have crossed on the Internet - and in court. Xiao's clash with him, and with Fang Xuanchang, revolves around a surgical procedure devised by Xiao that aims to restore bladder and bowel function in patients with spina bifida or spinal-cord injuries. Xiao reported an impressive $87 \%$ success rate for the operation, which involves re-routing nerves ${ }^{1,2}$. In 2005, he was nominated for membership of the Chinese Academy of Sciences, the elite body of the Chinese scientific world.

Following his nomination, people started posting questions about Xiao's claims on
Fang Shimin's website (http://fangzhouzi-xys. blogspot.com). Then in September 2005, Fang Shimin published an essay in Beijing Sci-Tech Report, which said that Xiao was not an associate professor at New York University as he states in his CV, but only an assistant professor. Furthermore, the article said that only 4 of the 26 English-language publications Xiao listed were journal articles - the rest being abstracts from conference proceedings.

It is not known if Fang Shimin's article affected the academy's decision, but Xiao was not made a member and has since sued Fang Shimin for libel five times. Fang Shimin, whose site has been criticized for giving contributors a platform for unjustified attacks on their enemies ${ }^{3}$, lost one case and won two, with the other two undecided. Meanwhile, criticism of the 'Xiao procedure' has continued. Last year, Fang Xuanchang published a series of articles questioning its efficacy, which may have prompted the attacks on him.

Beijing-based lawyer Peng Jian says he has interviewed 20-30 patients who have experienced side effects after undergoing the Xiao procedure, and who are seeking compensation. This summer, the first US trial of the treatment reported ambiguous results in The Journal of Urology $y^{4}$, and two journal editorials said it should be considered experimental ${ }^{4}$.

Fang Shimin, meanwhile, is unfazed by the attack. "It won't stop me," he says. "I will continue to do what I am doing." -

\footnotetext{
1. Xiao, C.-G. Proc. Int. Conf. Urol. Shanghai, 2-4 July (2005).

2. Xiao, C.-G. Eur. Urol. 49, 22-29 (2006).

3. Cyranoski, D. Nature 441, 392-393 (2006).

4. Peters, K. M. et al. J. Urol. 184, 702-708 (2010).
}

\section{Science safe in Brazil elections}

\author{
Next head of state unlikely to \\ upset the status quo.
}

\section{BY ANNA PETHERICK}

$\mathrm{L}$ ike many other Brazilians, the nation's scientists are hoping that the presidential elections of 3 October will bring as little change as possible. After nearly a decade of solid support for science from President Luiz Inácio Lula da Silva, his likely successor, Dilma Rousseff, has much to live up to.

Lula's own formal education may have been meagre, but during his seven years as president he has raised the status of science in Brazil by steadily increasing research funding (see chart) as a percentage of gross domestic product (GDP) - which itself has grown impressively (see Nature 465, 674-675; 2010). He has also elevated Brazil's scientific profile by writing numerous editorials on its science-development initiatives, including one in Scientific American in 2008, and his science minister of five years, Sérgio Rezende, has published research about spin-wave theory in Physical Review Letters while in office.

"The Lula government brought a very important increase in funding and did very important work in terms of policy-making and agenda setting," says Paulo Gadelha, president of the Fundação Oswaldo Cruz (Fiocruz) biomedical research institute in Rio de Janeiro. "It was the first time that we brought together the traditional areas related to industrial policy with those related to science funding, health and agriculture."

It has not all been good news, however. Lula's former environment minister, Marina Silva - who is now is standing against Rousseff - resigned in 2008 because she did not think the government was doing enough to protect the Amazon. Despite her concerns, 2009 figures showed that deforestation plunged to

\section{AN IMPRESSIVE RECORD}

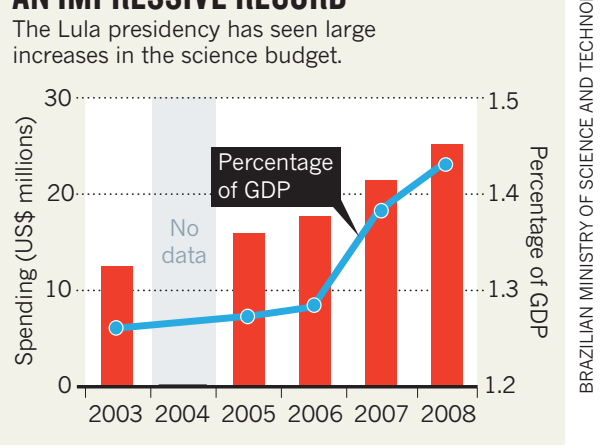




\section{Safety authority rebuts conflict claim}

\section{Greens highlight industry links in bid to discredit European food agency.}

\section{BY DECLAN BUTLER}

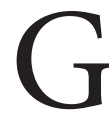
reen groups have long alleged that the European Food Safety Authority's (EFSA's) scientific risk assessments of food, animal feed and agrochemicals tend to be too industry friendly. But the criticisms intensified after last week's accusation of a conflict of interest at the very top of the organization.

On 29 September, José Bové, a French farmer and a representative of the Europe Ecology party in the European Parliament, alleged that Diána Bánáti - chair of the EFSA management board from October 2008 to 30 June this year - had failed to declare that in April 2010 she had joined the European board of directors of the International Life Sciences Institute (ILSI), a non-governmental organization that is funded by food companies and seeks to coordinate and fund research and risk assessment.

Bové provided no evidence that Bánáti's ILSI links had influenced her actions at EFSA, and the board has no direct role in the agency's risk assessments. EFSA points out that it has strict safeguards on conflicts of interest, but admits that the publicity over the affair risks harming public perception of its impartiality. Catherine Geslain-Lanéelle, EFSA's executive director, says that the agency has "learned lessons" from the recent attacks, and is considering introducing tougher rules for the chairs and vice-chairs of panels. "Public perception is important; we need trust," she says.

Bánáti is director general of Hungary's Central Food Research Institute in Budapest, and she remains on the EFSA board - a part-time post that is unpaid. EFSA says that the omission in Bánáti's declaration of interest - which was corrected last week — was an oversight on its part, and notes that ever since Bánáti joined the EFSA board in 2006, her membership of ILSI's scientific and advisory committee has been declared on EFSA's website.

Several other EFSA officials have links with
ILSI. For example, Milan Kováč, a prominent food scientist and government official in the Czech Republic, who is on the boards of EFSA and ILSI, is also a member of the scientific advisory board of the European Food Information Council, which is largely funded by food companies. Many EFSA scientific opinions also cite ILSI-sponsored studies.

ILSI insists that it is not a lobbying group. In a statement last week, the institute said that it seeks out top talent, and that it was "not surprising" that the same individuals are sought by other public-health bodies.

\section{CORRECTIONS}

In 'Science safe in Brazil elections' (Nature 467, 511-512; 2010) the graph should have read US\$ billions not US\$ millions.

In 'Brawl in Beijing' (Nature 467, 511; 2010), the correct link to Fang Shimin's website is www.xys.org. 